\title{
Why and how teachers use nature of science in teaching quantum physics: Research on the use of an ecological teaching intervention in upper secondary schools
}

\author{
H. K. E. Stadermann $\odot^{*}$ and M. J. Goedhart๑ \\ Faculty of Science and Engineering, Institute for Science Education and Communication, \\ University of Groningen, 9747 AG Groningen, Netherlands
}

(Received 17 May 2021; accepted 9 September 2021; published 2 November 2021)

\begin{abstract}
Students at upper secondary and college level in many countries are introduced to quantum physics (QP) in a mostly mathless course. Research shows that addressing epistemological and philosophical aspects would be beneficial for novice students' conceptual understanding. However, physics teachers seldom address these nature of science (NOS) aspects in their lessons. We take the view that teachers only implement these aspects if this serves their goals. This study explores whether experienced Dutch high school teachers, who are not trained for NOS teaching, address NOS in their QP lessons when provided with NOS-infused teaching resources. We based our framework on literature about pedagogic content knowledge and on the principles of the practicality of educational innovations. Teacher interviews $(N=10)$ supported by classroom observations provided insights into how and why teachers use specific elements from the resources. Our research reveals teachers' perspectives on teaching QP in secondary schools and why they think NOS aspects can be helpful to reach their teaching goals. Our findings support the view that conceptual QP is valuable for all students because an informed NOS view is vital for everybody in today's society. Additionally, we expect that an ecological intervention that supports teachers and at the same time recognizes their professionality and environment has potential implications for other fields of science education and could have a significant positive impact in classrooms.
\end{abstract}

DOI: 10.1103/PhysRevPhysEducRes.17.020132

\section{INTRODUCTION}

Quantum physics (QP) has been introduced as a compulsory topic in the physics curriculum at pre-university level in many countries [1] because of its scientific and societal importance. The unparalleled explanatory and predictive capacity of quantum theory has made it the basis of all contemporary models for the constituents of matter. Furthermore, the rapid development of information technology in the last decades has only been possible because of progress in QP. If secondary school physics only dealt with $19^{\text {th }}$-century physics, students would receive an outdated worldview and would be unaware of what to expect in higher education physics [2,3]. Additionally, science education researchers have labeled QP as one of the biggest cultural achievements of science [4,5], with a status similar to the Copernican and Darwinian revolutions. Therefore, learning about QP is regarded as being valuable not only for future scientists but for all students as

*h.k.e.stadermann@utwente.nl, she/her/hers

Published by the American Physical Society under the terms of the Creative Commons Attribution 4.0 International license. Further distribution of this work must maintain attribution to the author(s) and the published article's title, journal citation, and DOI. part of liberal education, even if they lack the mathematical background to comprehend the formalism of quantum theory $[2,3,6]$.

Indeed, we have seen an increasing number of studies on innovative ways to teach QP in secondary schools in the last few years [7-14]. Most of these innovations are concerned with new technical or cognitive approaches to teaching QP concepts; students' epistemological problems rooted in their ideas about the nature of physics are rarely explicitly addressed. Additionally, it is seldom mentioned what valuable learning opportunities QP offers for all those students who do not plan a career in quantum technology. Research suggests that discussing distinctive aspects of nature of science (NOS) in QP could be such a learning goal $[2,15]$. Explicit attention to NOS would additionally provide possibilities to address students' epistemological questions $[16,17]$. As teachers are instrumental in enabling students to benefit from NOS-informed QP approaches, we want to explore practicing teachers' views on teaching QP with explicit attention to NOS aspects.

At university level, the approach to QP is mainly mathematical; any philosophical interpretations of the formalism have commonly been neglected in teaching since the 1950s $[18,19]$. QP interpretations form the link between quantum formalism and the reality of experimental results. In contrast to the undisputed mathematical 
description of QP, its interpretations are responsible for the most famous and long-standing controversy in physics $[15,20,21]$. Fundamental ideas of different interpretations have even found their way into popular science media. For example, the so-called Copenhagen interpretation, attributed to Bohr and Heisenberg, postulates that particles such as electrons do not have a specific position but exist in a superposition of all possible measurement outcomes; only by making a position measurement, we create a specific outcome. However, in the pilot wave interpretation, advocated by famous physicists such as de Broglie, Bohm, and Bell, a quantum particle always has a well-defined position, although we miss information to exactly predict the outcome of position measurements. The ongoing controversy between proponents of different interpretations may seem purely philosophical, but it is also relevant for physics education because the way students imagine an electron largely depends on how QP is interpreted in their lessons [22].

The complex calculations used in university courses are beyond the math skills of secondary school students, and even simplified versions of quantum formalism do not usually belong to the school curriculum in most countries [1]. Therefore, secondary school teachers use a conceptual approach to QP. Here we use "conceptual QP" in the same sense as "conceptual physics" is commonly used in physics education to describe qualitative teaching of the central concepts of physics. Instead of focusing on mathematical expressions, the conceptual approach aims to engage students in model-based reasoning to construct and consolidate new concepts [23,24]. To acquaint students with some QP ideas, secondary education physics courses spotlight key concepts such as wave-particle duality, Heisenberg's uncertainty relationship and quantum physical atomic models. Although the presumed most significant obstacle-complex mathematics-is eliminated from this conceptual approach, learners still struggle with quantum concepts, mainly because QP phenomena contradict not only their common-sense notions but also the classical Newtonian physics they previously learned. It therefore seems necessary to guide students towards a new understanding of the physical world, recognizing the essential role of interpretations and models in QP.

\section{A. Why NOS aspects should be included in QP teaching}

The development of new models and interpretations is inherent to science in the making and part of the nature of science. NOS is a prominent and widely discussed term in science education. It refers to a spectrum of ideas that describe the development and status of scientific knowledge; it characterizes science as a human endeavor and includes epistemological, philosophical, and societal aspects $[25,26]$. While science education researchers do not always agree on how-if at all-NOS should be defined [27], it is beyond question that students should learn how scientific knowledge is constructed and how science is practiced. Some aspects of NOS, such as the importance of empirical evidence or the use of observations and inference, are commonly addressed in physics lessons because they relate to students' activities in practical inquiries [28]. However, aspects such as the role of scientific models, the tentativeness of scientific knowledge, or the existence of controversies in science are rarely discussed in school physics $[17,29,30]$. This omission is problematic because what is clearly visible in the development of the foundations of QP is quite unique for school physics: existing theories and models were not rejected but framed in their validity, and with the help of classical analogies and familiar words (electron, atom), completely new concepts were developed. Therefore, these NOS aspects play an essential role in learning QP.

Learners' difficulties with conceptual QP are often rooted in the tenacity of classical conceptions and rigid epistemologies [31]. To overcome these problems, many researchers advocate enriching conceptual QP lessons with NOS themes related to philosophy and epistemology $[2,15,16,32,33]$. Philosophical and epistemological issues have always been associated with the development of QP concepts. Famous examples are Schrödinger's cat and the Bohr-Einstein debates about the meaning of the mathematical formalism for reality [34]. Table I shows more examples of how NOS aspects are linked to the content of the QP curriculum.

In physics education literature, we find two main reasons why NOS can help students learn conceptual QP. First, if historical and controversial philosophical elements are addressed adequately, physics is more appealing to students, as they experience it as a living, human endeavor instead of a rigid collection of abstract facts $[35,36]$. Second, discussing NOS aspects such as scientific controversies and the historical development of quantum theory can be helpful to overcome conceptual problems [15,37-40]. For example, authors argue that the conceptual difficulties students commonly experience are very similar to those of pioneering physicists during the development of quantum theory. Therefore, NOS helps students to construct knowledge by addressing the historical development of physics concepts [40-42]. Additionally, some researchers state that discussing philosophical questions is important for students who are encountering QP for the first time $[43,44]$ because, even if not intended, NOS issues are always part of conceptual QP teaching. Whenever invisible quantum entities, such as electrons, are visualized in textbooks, computer simulations or animations, the developers make implicit interpretational choices, which might lead to misconceptions. Additionally, teachers unavoidably interpret mathematical formalism and influence the development of students' ideas about QP concepts by using models, metaphors, or analogies [45-48]. 
TABLE I. Examples of connections between NOS and QP content for teaching.

\begin{tabular}{|c|c|c|c|}
\hline NOS aspect & Example of intended NOS views & Related QP items & $\begin{array}{l}\text { Examples of how the NOS aspect can be } \\
\text { explicitly addressed in QP teaching }\end{array}$ \\
\hline $\begin{array}{l}\text { The role of scientific } \\
\text { models }\end{array}$ & $\begin{array}{l}\text { Scientific models are not a complete } \\
\text { representation of reality, but they } \\
\text { serve to explain or predict certain } \\
\text { aspects of phenomena. }\end{array}$ & $\begin{array}{l}\text { - Wave-particle duality } \\
\text { - }{ }^{*} \\
\text { - Atomic modelectric effect } \\
\text { - Particle in a box } \\
\text { - }\end{array}$ & $\begin{array}{l}\text { Depending on the situation, either the wave } \\
\text { model or the particle model is useful to } \\
\text { describe electrons or light. Some } \\
\text { properties of atoms can be illustrated } \\
\text { with the Bohr model, but to explain the } \\
\text { existence of atomic energy levels, we use } \\
\text { the 'particle in a box' model. }\end{array}$ \\
\hline $\begin{array}{l}\text { The tentativeness } \\
\text { of scientific } \\
\text { knowledge }\end{array}$ & $\begin{array}{l}\text { Scientific knowledge is, in principle, } \\
\text { always open to development, } \\
\text { warranted change and improvement. }\end{array}$ & $\begin{array}{l}\text { - Quantum tunneling } \\
\text { - Double slit experiment } \\
\text { with single particles }{ }^{*} \\
\text { - Atomic energy levels }\end{array}$ & $\begin{array}{l}\text { It is not possible to explain these quantum } \\
\text { phenomena with Newtonian physics. }\end{array}$ \\
\hline $\begin{array}{l}\text { The role of } \\
\text { controversies in } \\
\text { science }\end{array}$ & $\begin{array}{l}\text { Discussions and disagreements about } \\
\text { scientific ideas are essential in } \\
\text { scientific development. Different } \\
\text { interpretations may exist. }\end{array}$ & $\begin{array}{l}\text { - Different interpretations } \\
\text { of QP (what quantum } \\
\text { theory means for } \\
\text { reality) }\end{array}$ & $\begin{array}{l}\text { There is no consensus about the } \\
\text { (need for) interpretations of quantum } \\
\text { theory. Different scientists adhere, } \\
\text { for example, to the Copenhagen } \\
\text { (or agnostic), the pilot wave, or the } \\
\text { many-worlds interpretation. }\end{array}$ \\
\hline
\end{tabular}

*Item listed in Dutch exam syllabus.

The aforementioned arguments from physics education literature explain how NOS is helpful for learning QP. From the viewpoint of NOS learning, a relevant science context is crucial [49-51], and it is argued that QP could provide such a context. In conceptual QP, for example, students can realize that a model or analogy cannot explain all the properties of an electron and that controversy between scientists is an essential element in the development of scientific knowledge [52]. Additionally, if students themselves discuss the use of scientific models or rival interpretations, they experience an essential scientific practice: debating various viewpoints to obtain a better conceptual understanding [38].

\section{B. Why NOS aspects are not included in QP teaching \\ 1. Exam syllabus and textbooks}

There are no mandatory NOS aspects in the QP section of the national final exam syllabus for physics in the Netherlands and most other countries which assess this topic at secondary school level [1]. As long as NOS is not one of the explicitly stated learning objectives in the curriculum, teachers do not see it as their task to teach it $[53,54]$. Additionally, textbooks, the most commonly used teaching resource in physics classrooms, rarely support teachers in their integration of NOS aspects. Generally, most physics textbooks stress science as a body of knowledge with little attention to NOS [55].

\section{Traditional physics lessons; teachers' and students' expectations}

Teachers who do not see the utility value of informed views of certain NOS aspects are unlikely to include these
NOS aspects in their physics lessons. A recent study on the use of controversies in science lessons revealed that all participating teachers indicated that controversy is essential to science, but they preferred to discuss it with students outside of class. In the opinion of the participants, teaching "the facts" is most important. They assumed that discussing scientific controversies might confuse students rather than help them in the national exams [39].

The Norwegian ReleQuant project in upper secondary classrooms is the only reported broadly implemented teaching approach with a focus on qualitative understanding, NOS, history, and philosophy of QP [56]. The webbased instructional materials in this project include several activating pedagogies stimulating students' philosophical and epistemological reflections. In an evaluation of the project, in addition to positive results, the researchers found that students were frustrated by tasks such as discussing their interpretational views on QP because they lacked the possibility to check whether their answer was correct or not; students also did not recognize NOS aspects as learning goals in their own right [57]. The authors explain students' resistance to elements of the new approach as being a result of their expectations and socialization in traditional physics classrooms.

\section{Pedagogic content knowledge}

Although most Dutch physics teachers hold a master's degree in physics and have attended QP courses at university, these courses concentrate on mathematical formalism rather than interpretational and conceptual aspects. Additionally, QP had been introduced into the upper secondary curriculum in the Netherlands four years ago, 
and the majority of teachers were not prepared to teach conceptual QP and lack a broad repertoire of QP pedagogical content knowledge (PCK) $[58,59]$. To describe the dynamic construct of PCK, we adopt the five PCK subcategories of Magnusson et al. [60], which are teachers' personal knowledge and beliefs about (i) the goals and purpose of subject teaching; (ii) curriculum content; (iii) students' situationspecific learning difficulties; (iv) assessment of subject matter; and (v) topic-specific instructional strategies. Teacher's lack of PCK subcategories (ii)-(v) is a natural start-up problem for new curriculum content. How their teaching of QP will develop depends largely on teachers' knowledge and beliefs about purposes and goals for teaching QP in secondary school [PCK subcategory (i)]. Therefore, part of our research concentrates on revealing teachers' ideas about the purposes of teaching QP. Unlike others, who describe a separate "NOS PCK" developed in NOS courses [61], we adopt Van Dijk's [62] notion of PCK, which contains knowledge of topic-specific NOS aspects, that "emerge from the content that is being taught and should not be treated as general features that can be placed into a particular context when teaching science." [62].

Even without participating in a NOS course, teachers might feel that NOS aspects such as historical, philosophical, and epistemological themes are directly related to learning conceptual QP. Therefore, in this study, we consider NOS as a possible educational goal and part of teachers' PCK.

Before formulating the resulting research questions in Sec. I. D, we briefly introduce a key instrument for this study; the instructional materials for teaching QP with explicit attention to NOS, and describe how these materials are used in interventions.

\section{Teaching material \\ 1. Practicality}

While the entanglement of QP and NOS is apparent, even a perfect theoretically and pedagogically developed innovative teaching module is useless if teachers do not use it. In everyday classrooms, teaching comprises much more than finding the best cognitive route for students to reach the learning goal; in a fast-paced, information-rich environment, teachers are expected to implement lesson plans, prepare for exams, enforce school rules and at the same time build interpersonal relationships with students to help, inspire, correct, comfort, challenge or support them, not only in their subject learning but also in their emotional and general cognitive development. Therefore, implementing any "research-based" teaching strategy-with new subject content and pedagogies-is not straightforward for teachers. Teaching strategies which are not perceived as useful are unlikely to make their way into classrooms.

To achieve a successful implementation of teaching innovations, Doyle and Ponder [63] distinguish three preconditions or practicality dimensions: (1) Instrumentality: Rather than imposing abstract principles (e.g., NOS tenets) on teachers, innovative teaching practices should be translated into concrete classroom procedures; (2) congruence: Practices should fit the way teachers perform classroom activities, their self-perception, and the classroom setting in which they work; and (3) low cost: Practices should not demand a significant amount of time and effort. In a followup study, Westbroek, Janssen, and Doyle [64] found that it is essential to connect teachers' professional core goals with the proposed innovation. These goals reflect teachers' fundamental beliefs about good teaching. Therefore, useful teaching resources support teachers' individual teaching goals, add value to their expertise and ideally work with little extra investment of time and effort.

\section{Ecological intervention}

Because QP is a new curriculum domain and thus not burdened with ingrained, difficult to change teaching practices, it is particularly suitable to develop new PCK, which includes relevant NOS elements. This QP PCK can be supported by teaching or learning material that meets the above specified criteria of Doyle and Ponder [63]. Janssen et al. [65] showed how building blocks, or lesson segments, can be used to customize available teaching resources. Adapting, recombining, or rearranging the order of lesson segments can lead to different teachinglearning processes suitable for specific demands of classroom ecologies [66]. Elaborating on this idea, we developed buffet-style teaching resources to support teachers' QP PCK. The design of the resources was guided by Doyle and Ponder's prerequisites for successful innovation and findings from research on students' learning difficulties in QP, and topic-specific teaching strategies were applied in the teaching material. The development and further details on the content of these learning resources will be presented in a separate publication [67].

The educational material was made available to teachers in the form of a presentation containing 142 editable presentation slides, covering all the learning objectives from the Dutch QP curriculum. Additionally, we intertwined NOS-related elements into building blocks to facilitate (or tempt) teachers to address NOS aspects in QP teaching. To make the resources instrumental, we prepared elements teachers could use directly in the classroom, such as concept questions for online voting (see Fig. 1), discussion prompts (see Fig. 2), and a selection of publicly available explanatory videos. The buffet-style format made the resources congruent because, by selecting specific parts of the slide presentation, teachers tailor the material to their specific situation and their preferred teaching activities. The readymade slide presentations with pre-arranged online concept questions and short videos make the material easy to use in classrooms, and therefore low cost.

In contrast to a conventional instructional intervention, where teachers have to follow steps precisely, we call our approach an ecological intervention. Following 


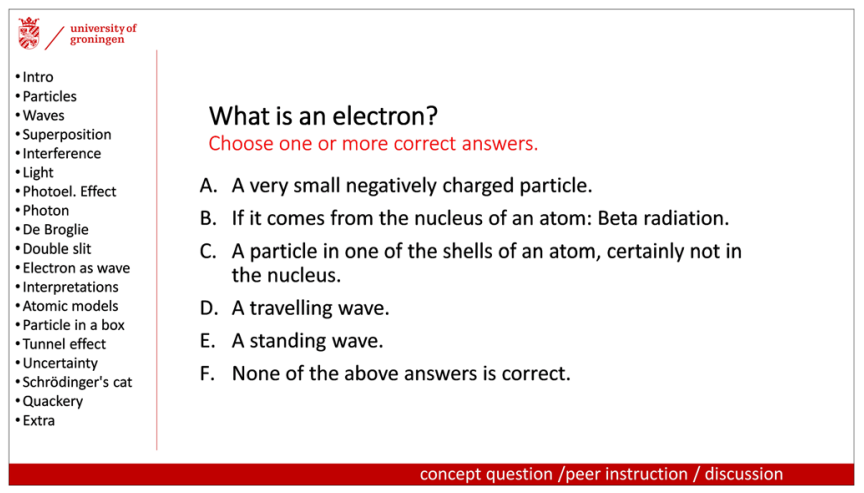

FIG. 1. Example of a slide with a concept question.

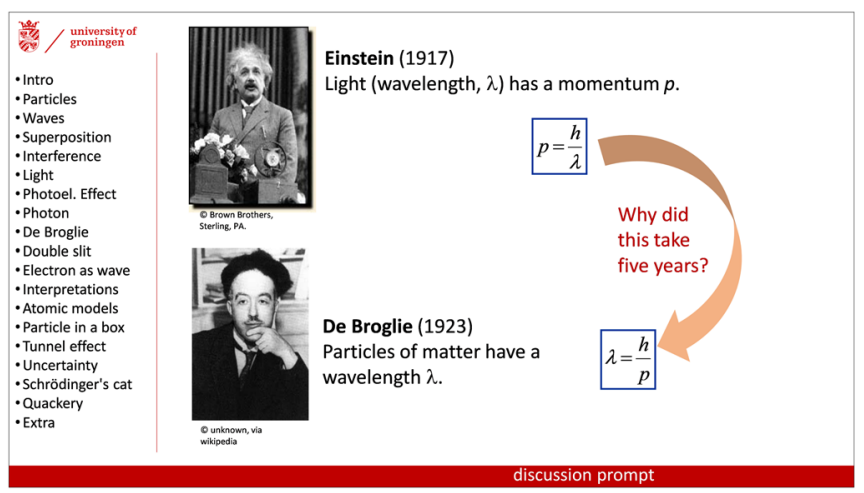

FIG. 2. Example of a slide with a discussion prompt.

Janssen et al. [66], we adopt Doyle's [68] ecological perspective on the classroom as a social-ecological environment.

From this perspective, it is possible to describe how teachers' decisions influence and depend on a complex interaction between personal characteristics and environmental factors such as student population, technical possibilities, time constraints, and behavioral patterns. An ecological teaching intervention provides teachers with a flexible toolbox with various possibilities for situation-dependent actions.

In our context, a teacher could, for example, skip or delete slides with discussion prompts if there is not enough time for discussions or decide to discuss the videos about different interpretations of QP if they consider this as meaningful. They could also change the order of the slides to make them compatible with the textbook they use. Table II provides an overview of the content items that relate to NOS aspects (scientific models, tentativeness, and controversies in science). Table II also shows the various activity formats supported by the instructional material.

To illustrate the slide presentation, we show two (translated) slides in Figs. 1 and 2. In contrast to common concept questions, the question "What is an electron?" does not have a straightforward, correct answer and provokes many new questions. It could even be discussed if the question itself is valid. Discussions can be facilitated by first collecting individual answers using a web-based student response system with smartphones, followed by peer discussion [69]. Teachers could alternatively choose to use the multiple answers to begin a class-wide discussion on NOS aspects such as "the role of scientific models," "the tentativeness of science knowledge," or general epistemological and philosophical questions about our possibilities to understand reality. Teachers could, on the other hand, skip the whole question and only use the slides which contain explanations or teach from the textbook instead of the provided slide presentation. Figure 2 shows a slide that offers a prompt for an open discussion. Again, teachers could remove the question "Why did this take five years?" and just present it as the transformation of a formula.

\section{Research questions}

This study's context is defined by a recent curriculum change, which highlighted in-service physics teachers' lack of experience in teaching QP and the fact that NOS is not part of mandatory teaching requirements. To support teachers' PCK for qualitative QP, they were offered easyto-enact and easy-to-adapt (buffet-style) teaching or learning material with several possibilities to explicitly address and integrate NOS aspects in QP lessons. When teachers choose to use NOS teaching opportunities in the instructional material, we wish to explore their motives. In Shulman's PCK framework [58,59], addressing NOS aspects in the lesson supports their beliefs about the purpose of QP teaching or, viewed from the practicality perspective of Doyle and Ponder [63,66], NOS fits in teachers' goals of QP teaching. Through teacher interviews, lesson observations, and learning activity responses from students, we attempt to answer the following questions:

RQ1: Which NOS aspects-if any-do the teachers address in their QP lessons, and what teaching activities do they choose for this?

RQ2: How do teachers' goals in QP lessons relate to these NOS aspects?

The order of the research questions reflects our evidencebased research design. As explained in the Sec. II, we ask questions to elicit teachers' intended goals based on their actual classroom activities. We choose not to ask about teachers' goals first. In this way, we avoid that a teacher might state desirable goals that are not realized in real lessons. This enhances the validity of our results.

\section{RESEARCH DESIGN AND METHODS}

In this study, we aim to collect evidence of teachers' use of NOS aspects in teaching QP and to obtain insights into why and how they address NOS in their physics classrooms. To understand our methodological choices and to emphasize the specific nature of this study, we first distinguish it from other 
TABLE II. Overview of the structure, content, and supported activities of the instructional material.

\begin{tabular}{|c|c|c|c|c|c|c|c|c|c|c|c|c|c|c|c|c|}
\hline \multirow[b]{2}{*}{$\begin{array}{l}\text { Section of } \\
\text { slide } \\
\text { presentation }\end{array}$} & \multirow[b]{2}{*}{ Covered content items } & \multirow[b]{2}{*}{ 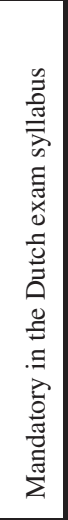 } & \multicolumn{3}{|c|}{$\begin{array}{l}\text { Addressed } \\
\text { NOS } \\
\text { aspect }\end{array}$} & \multicolumn{11}{|c|}{$\begin{array}{l}\text { Material to support } \\
\text { instructional activities }\end{array}$} \\
\hline & & & $\begin{array}{l} \\
\\
\frac{a}{0} \\
0 \\
\Sigma \\
\end{array}$ & \begin{tabular}{|c|} 
\\
\\
0 \\
0 \\
0 \\
0 \\
0 \\
0 \\
0 \\
0 \\
0 \\
0 \\
0
\end{tabular} & 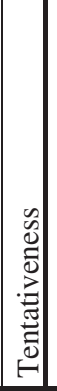 & 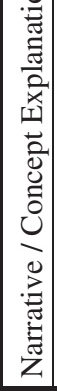 & 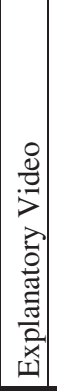 & 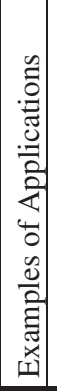 & 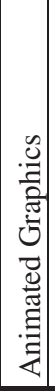 & \begin{tabular}{|c|} 
\\
\\
0 \\
0 \\
$: 0$ \\
0 \\
0 \\
0 \\
0 \\
0 \\
0 \\
0 \\
0 \\
0 \\
0 \\
0 \\
0 \\
0 \\
0
\end{tabular} & 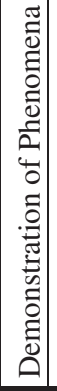 & 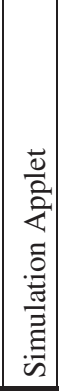 & $\begin{array}{c}0.0 \\
. \\
0 \\
0 \\
0 \\
0 \\
0 \\
0 \\
00 \\
.5 \\
0 \\
0 \\
0 \\
0 \\
0 \\
0 \\
0 \\
0 \\
0\end{array}$ & 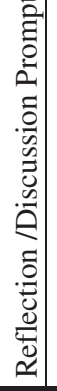 & \begin{tabular}{|c|} 
\\
\\
\\
\\
0 \\
.0 \\
0 \\
0 \\
0 \\
0 \\
0 \\
0 \\
0 \\
0 \\
0 \\
0
\end{tabular} & 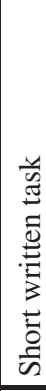 \\
\hline \multirow{5}{*}{ Introduction } & Electrons as particles (repetition) & yes & $x$ & & & & & $\mathrm{O}$ & & & & & $\mathrm{O}$ & & $\otimes$ & \\
\hline & Atomic models (repetition) & yes & $x$ & & $\times$ & O & & & & O & & & & $\otimes$ & & \\
\hline & Waves (repetition) & yes & & & & $\mathrm{O}$ & & $\mathrm{O}$ & O & $\mathrm{O}$ & $\mathrm{O}$ & $\mathrm{O}$ & & & 0 & \\
\hline & Wave interference & yes & & & & 0 & & O & O & $\mathrm{O}$ & $\bigcirc$ & O & O & & 0 & \\
\hline & Superposition & yes & & & & 0 & & & $\mathrm{O}$ & & & & & & 0 & \\
\hline \multirow{4}{*}{ Light } & Light as wave & yes & & & & $\mathrm{O}$ & & $\mathrm{O}$ & & 0 & & & $\mathrm{O}$ & & & \\
\hline & Double slit experiment with light & yes & $x$ & $x$ & $\times$ & $\otimes$ & & & & & $\mathrm{O}$ & $\otimes$ & & & 0 & \\
\hline & Photoelectric effect & yes & $x$ & & & 0 & & 0 & & O & & 0 & & 0 & $\otimes$ & \\
\hline & Quantization of light & yes & $x$ & $x$ & & $\otimes$ & & & & $\otimes$ & & & & & O & \\
\hline \multirow{5}{*}{ Matter } & Wave-particle duality & yes & $x$ & $x$ & $\times$ & $\otimes$ & & & & $\otimes$ & & O & & O & $\otimes$ & \\
\hline & Double slit exp. with particles & yes & $x$ & $x$ & $\times$ & $\otimes$ & $\otimes$ & & & & & O & & $\otimes$ & O & $\otimes$ \\
\hline & Probability distribution & yes & & & & 0 & & & & & & O & & & & \\
\hline & De Broglie wavelength & yes & $x$ & & & 0 & & 0 & & 0 & & & 0 & $\otimes$ & $\otimes$ & \\
\hline & Electron microscope & yes & & & & $\mathrm{O}$ & & 0 & & & & & 0 & & & \\
\hline \multirow{3}{*}{$\begin{array}{l}\text { QP inter- } \\
\text { pretations }\end{array}$} & Copenhagen interpretation & no & & $x$ & & 0 & $\otimes$ & & & & & & & $\otimes$ & & \\
\hline & Many worlds interpretation & no & & $\times$ & & & $\otimes$ & & & & & & & & & \\
\hline & Pilot wave interpretation & no & & $x$ & & & $\otimes$ & & & & & & & & & \\
\hline \multirow{3}{*}{$\begin{array}{l}\text { Atomic } \\
\text { models }\end{array}$} & Discreet energy levels & yes & $x$ & & & $\otimes$ & & O & O & $\mathrm{O}$ & & $\mathrm{O}$ & O & $\otimes$ & O & $\otimes$ \\
\hline & $\begin{array}{l}\text { Particle in a one-dimensional } \\
\text { box }\end{array}$ & yes & $x$ & & & $\otimes$ & & O & & O & & O & 0 & $\otimes$ & O & $\otimes$ \\
\hline & Hydrogen atom quantum model & yes & $x$ & & $\times$ & O & & 0 & & & & & 0 & $\otimes$ & & $\otimes$ \\
\hline \multirow{3}{*}{$\begin{array}{l}\text { Phenomena, } \\
\text { principles }\end{array}$} & $\begin{array}{l}\text { Heisenberg's uncertainty } \\
\text { principle }\end{array}$ & yes & & & & 0 & & 0 & $\mathrm{O}$ & O & & & & & 0 & \\
\hline & Quantum tunneling & yes & $x$ & & & 0 & & $\mathrm{O}$ & 0 & & O & 0 & & 0 & $\otimes$ & \\
\hline & Alpha decay & yes & $x$ & & & $\otimes$ & & $\mathrm{O}$ & & & & & & & & \\
\hline \multirow{2}{*}{$\begin{array}{l}\text { Applications, } \\
\text { technology }\end{array}$} & Scanning Tunneling Microscope & yes & & & & $\mathrm{O}$ & $\mathrm{O}$ & $\mathrm{O}$ & & & & & & & & \\
\hline & Quantum dots & no & & & & 0 & & 0 & & & & & & & & \\
\hline a'Legend: & $\begin{array}{l}=\text { suggested NOS aspect in the m } \\
=\text { supported teaching activity (no } \\
=\text { intended NOS aspects in instru }\end{array}$ & $\begin{array}{l}\text { aterial } \\
\text { explic } \\
\text { ctiona }\end{array}$ & & $\begin{array}{l}\text { JOS } \\
\text { tivity }\end{array}$ & & & & & & & & & & & & \\
\hline
\end{tabular}

types of research with thematic and methodological overlap. In contrast to many other science education studies, our aim is not to investigate the effectiveness of NOS teaching material for students; instead, we focus on teachers' practices and goals. We also do not probe the characteristics of educators who use NOS in their classrooms or the problems they experience. Our research is performed in natural, authentic school conditions and deals with upper secondary
QP courses, in which teachers have the freedom to decide how to reach their teaching goals. With an ecological intervention, we acknowledge teachers' professionality and their expertise to choose teaching strategies useful for their specific situation. An in-depth analysis of interviews gave us insights into why and how different teachers in a similar situation use NOS in their lessons. Figure 3 gives an overview of our research design. 


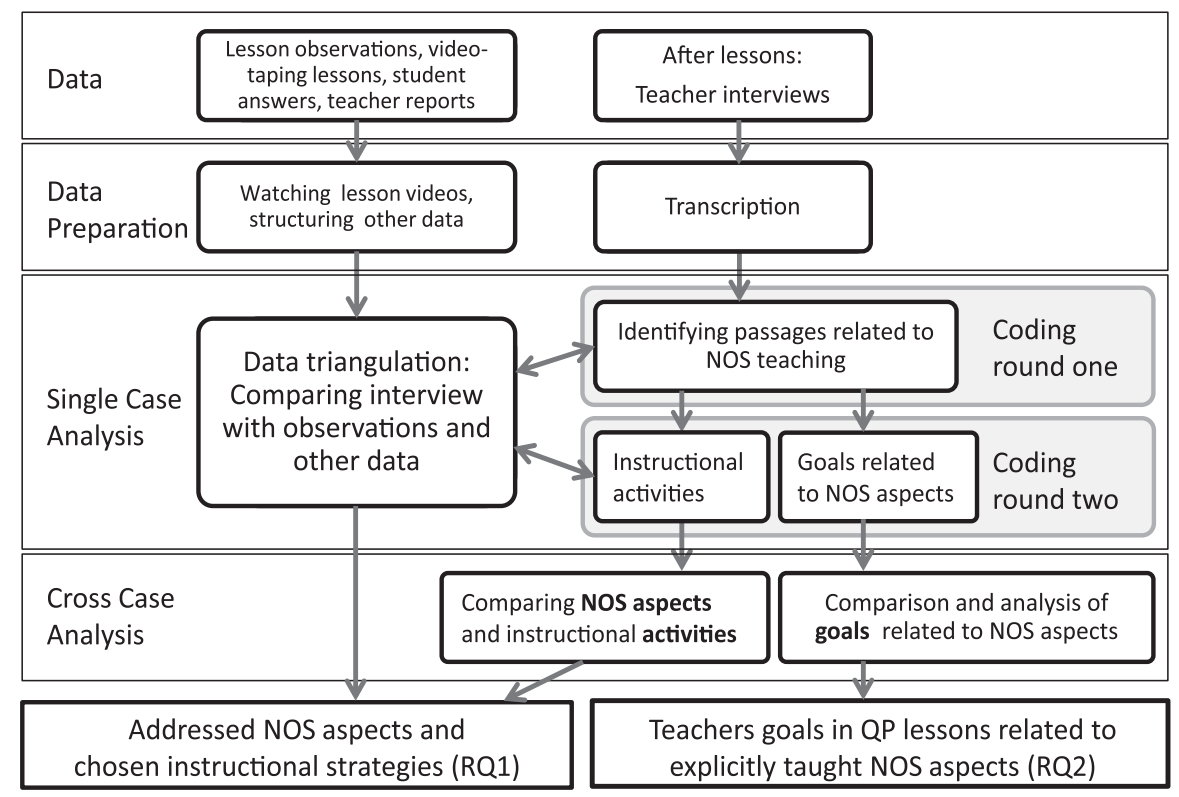

FIG. 3. Research design overview.

\section{A. Context and participants}

Since 2016, QP has been a mandatory part of the national written physics exam in the Netherlands and is usually taught in pre-exam classes (grade 12, students aged 17-18). NOS is not explicitly included in the QP learning objectives. The official national curriculum does not prescribe any instructional framework or pedagogy for teaching.

Ten physics teachers from six different Dutch public secondary schools volunteered to participate in the study; three of them taught parallel classes. Table III gives an overview of teachers' characteristics (names are changed). Because we wanted to investigate the participating teachers' authentic needs, practices, and lesson goals, they were not pressured to use the material in a specific way. Four to six weeks before teaching QP, the teachers received the full teaching material and a written instruction about how students could use the online voting system on their smartphones for concept questions. Additionally, teachers received a short individual oral introduction to the material to explain how the slide presentation could be adapted and how peer instruction could be effectively used. NOS aspects were not discussed during this instruction. Before and during the teaching period, the first author was available for individual questions via email.

\section{B. Data sources and data collection}

The primary data source for this study is teacher interviews; we collected additional data (left side in Fig. 3) with the aim to triangulate the interview results. For this, we observed at least one lesson of each class, and we recorded

TABLE III. Teacher characteristics and data availability.

\begin{tabular}{|c|c|c|c|c|c|c|c|c|c|c|}
\hline \multirow[b]{2}{*}{ Name } & \multirow[b]{2}{*}{ Gender } & \multirow[b]{2}{*}{$\begin{array}{l}\text { Age } \\
\text { group }\end{array}$} & \multirow[b]{2}{*}{$\begin{array}{l}\text { Years teaching } \\
\text { Grade } 12\end{array}$} & \multirow[b]{2}{*}{$\begin{array}{l}\text { Educational } \\
\text { Background }^{\text {a }}\end{array}$} & \multirow[b]{2}{*}{$\begin{array}{l}\text { Taught } \\
\text { groups }\end{array}$} & \multicolumn{4}{|c|}{ Available lesson data } & \multirow[b]{2}{*}{$\begin{array}{c}\text { Interview } \\
\text { length (min) }\end{array}$} \\
\hline & & & & & & $\begin{array}{l}\text { Observ. class } \\
\text { periods }\end{array}$ & $\begin{array}{c}\text { Video class } \\
\text { periods }\end{array}$ & $\begin{array}{l}\text { Student } \\
\text { responses }\end{array}$ & $\begin{array}{l}\text { Teacher } \\
\text { reports }\end{array}$ & \\
\hline Nina & $\mathrm{f}$ & $30-39$ & $5-10$ & $\mathrm{~A}$ & 2 & 4 & 0 & $\mathrm{CQ}, \mathrm{PI}$ & 4 & 36 \\
\hline Emma & $\mathrm{f}$ & $40-49$ & $5-10$ & A & 1 & 1 & 0 & CQ, WT, PI & 2 & 35 \\
\hline Daan & $\mathrm{m}$ & $40-49$ & $5-10$ & $\mathrm{~B}$ & 1 & 2 & 0 & none & 1 & 58 \\
\hline Oliver & $\mathrm{m}$ & $40-49$ & $>10$ & $\mathrm{~A}$ & 1 & 1 & 0 & CQ & 1 & 35 \\
\hline Karim & $\mathrm{m}$ & $>50$ & $>10$ & $\mathrm{~A}$ & 1 & 2 & 0 & PI & 1 & 52 \\
\hline Liam & $\mathrm{m}$ & $>50$ & $>10$ & $\mathrm{~A}$ & 2 & 2 & 0 & $\mathrm{CQ}, \mathrm{PI}$ & 0 & 38 \\
\hline Ben & $\mathrm{m}$ & $>50$ & $>10$ & A & 2 & 4 & 0 & CQ, PI & 6 & 60 \\
\hline Hanna & $\mathrm{f}$ & $>50$ & $>10$ & A & 1 & 3 & 3 & CQ, WT, PI & 2 & 40 \\
\hline Tim & $\mathrm{m}$ & $>50$ & $>10$ & A & 1 & 3 & 3 & PI & 0 & 40 \\
\hline Milan & $\mathrm{m}$ & $>50$ & $>10$ & $\mathrm{C}$ & 1 & 3 & 3 & none & 0 & 45 \\
\hline
\end{tabular}

${ }^{\mathrm{a}}$ Educational background: $\mathrm{A}=\mathrm{MSc}$ (physics) plus postgrad. teacher training; $\mathrm{B}=\mathrm{M} . \mathrm{Ed}$ (physics); $\mathrm{C}=\mathrm{PhD}(\mathrm{physics})$ plus postgrad. teacher training.

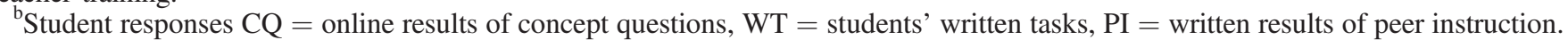


lessons from three schools to see how teachers implemented the material. Additionally, we collected student responses to online concept questions and written tasks and emails from teachers reporting on the progress of the lessons or asking questions about the provided material. The data collection during lessons reflects the possibilities and problems of data taking in everyday school life. Therefore, we do not see the diversity in our dataset as a shortcoming but rather as a characteristic of an ecological intervention study.

To understand teachers' goals related to integrating NOS into their QP lessons (RQ 2), the first author conducted individual semistructured interviews (35 to $60 \mathrm{~min}$ ) with each teacher (see the Appendix [70] for the interview guide). These were audiotaped and transcribed verbatim for further analysis. For the interviews, we adapted the technique of practical reasoning from Janssen et al. [66] to find the goals that underlie teachers' decisions regarding the parts of the instructional materials they used. The interviews followed the thematic structure of the instructional materials (Table II), and teachers were asked to explain whether and how they used each part of the slide presentation. If teachers mentioned that they addressed NOS aspects, the interviewer asked follow-up questions to understand why they decided to teach QP in this way. Through this interview strategy, we got detailed insights into teachers' intentions, goals, and students' responses to each element of their lessons. In this study, we focus only on the goals teachers mentioned when addressing themes related to NOS.

\section{Data analysis}

In the first round, three anonymized interviews, selected on diversity, were individually analyzed by three researchers, the two authors, and a university physics education lecturer. First, each researcher filtered out all fragments that were related to NOS teaching and deductively coded for the three NOS aspects on which this research focuses: role of models, tentativeness, and controversies (see Tables I and II). Additionally, we coded interview passages about NOS aspects that did not completely fit into one of the three targeted NOS aspects. A comparison revealed that all researchers selected the same interview passages and decided that henceforth only the first author would select the relevant passages. To cover the NOS statements that did not fit in the three targeted aspects (see Table II), we agreed on adding two new codes: "Limitations of science" for interview passages in which teachers discussed unanswered questions in QP, and "Science as Human Endeavor" in which teachers highlighted the importance of scientists in historical contexts. This first round of coding hence provided us with interview excerpts on five NOS aspects (see Table IV) which we analyzed further.

In the second round, all three researchers independently coded the selected interview passage from the first three interviews for (a) specific instructional strategies and (b) reasons and goals teachers mentioned for using-or not using-NOS-related teaching activities. The codes for teaching activities were based on the NOS supporting instructional material: Narrative/explanation (for mainly informative teacher monologues, supported by the instructional material), explanatory video, concept question, and short written task stem directly from the NOS-supporting instructional material (see Table II), and peer instruction and dialogic discourse specify how the discussion prompts or concept questions were used in the classroom. This part of the coding was deductive and straightforward without any discrepancy between the three researchers. It was therefore decided that the first author coded the remaining interviews. To improve validity and reliability, the first author triangulated the findings with other available data (lesson observations, teacher reports, and digital and written student responses).

For the coding of goals, we chose an inductive thematic analysis [71] to be open for all possible teaching goals which arose during the interviews. A comparison between the coding by the three researchers of the first three analyzed interviews revealed differences in how finegrained each researcher formulated the themes. After discussing all themes of the first three interviews, we agreed on combining some themes with similar meanings in our context; for example, the preliminary themes make students think scientifically, stimulate critical thinking, stimulate reasoning, and scientific argumentation were merged to "stimulate thinking and argumentation." We also agreed that double coding would do justice to the teachers' statements in some cases. After agreeing on five themes of goals (see Table IV), the two authors independently analyzed three additional randomly selected interviews. The five goal codes proved to be broad and varied enough to categorize all emerging statements, and disagreements were discussed until consensus was reached. The first author then analyzed the remaining four interview transcripts. She consulted the second author for some unclear cases.

\section{RESULTS}

Table IV provides an overview of the results of our interview analysis. Data triangulation shows that teachers' interview statements about which NOS aspects they addressed and the use of specific teaching activities agree with what we observed in classrooms.

\section{A. NOS aspects that were addressed in QP lessons}

From Table IV, we see that nine of the ten teachers addressed one or more NOS aspects and that most teachers (8/10) discussed the role of scientific models in their QP lessons. The tentativeness of scientific knowledge was a topic in the lessons of five teachers. 


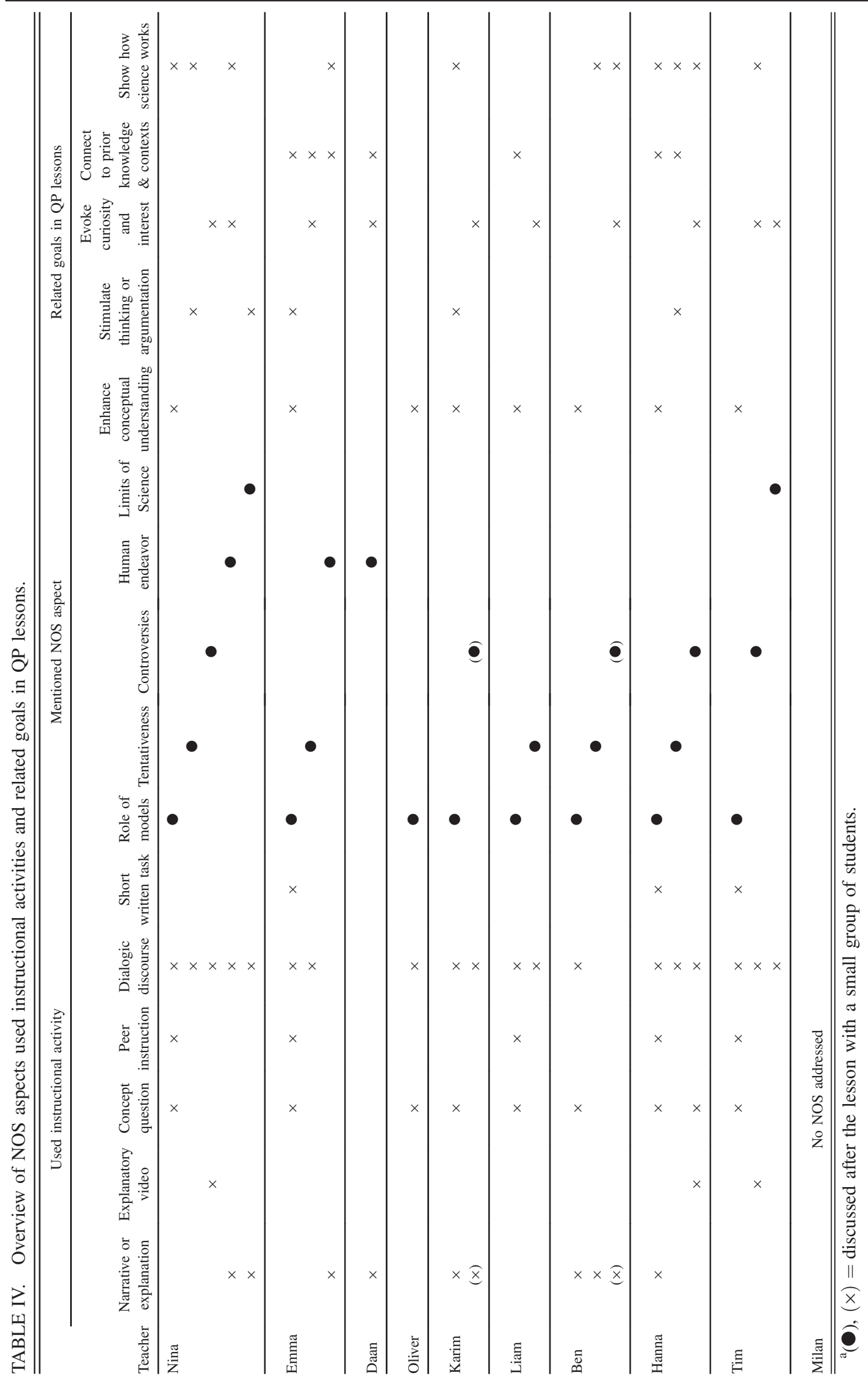


Also, five teachers used different currently discussed QP interpretations to thematize controversies in science. Two of them only did it after the lesson with a small group of students because they did not want to "waste" time on a subject that is not in the exam syllabus and presumably would not interest many students. Additionally, three teachers stressed the development of QP as a human endeavor, and two teachers explicitly addressed the limits of science.

One teacher (Milan), interestingly, the one who holds a $\mathrm{Ph} . \mathrm{D}$. in quantum theory, clearly expressed that he did not see any usefulness for NOS in teaching QP.

I hardly ever talk about models. [...] I don't think it's that interesting. I'm pragmatic; quantum mechanics works perfectly, so it is easy to work with. When we interpret it, we lose it. [...] Yes, it is a conscious choice not to discuss interpretations. I really don't find the philosophical interpretation of quantum interesting. I think it is unfinished. (Milan)

\section{B. Chosen instructional activities in which NOS aspects were addressed}

A comparison of the applied instructional activities (Table IV) shows that teachers created very different lessons with the material provided, reflecting their personal preferences. For example, in the observed lessons, we could characterize Nina and Ben as talented storytellers; their students listened attentively and participated in the interactive elements of narratives and explanations. Although both teachers used monologues, they constantly connected with the students by appealing to their imagination, as illustrated in this passage from Nina's lesson.

...try to imagine how it was at that time. [pause] You wrote letters to your colleagues about your thoughts, your ideas. It was not immediately on the internet. [pause] There was no internet.

A different instructional strategy was visible in Hanna, Emma, and Tim's lessons: often walking through the classroom, they skillfully involved students in dialogues, questions, and discussions. Emma explained that this is her preferred way of teaching: I don't really like to lecture, so I try to arrange for them to talk to each other.

Overall, episodes of dialogic discourse were the preferred classroom activity to address NOS aspects. We use the term "dialogic discourse" to refer to classroom situations in which teachers acted as facilitators of a wholeclass dialogue in which students were encouraged to express their ideas and respond to others. For example, teachers asked students to give argued reasons for their answers to concept questions and ensured that different students were intellectually engaged in the exchange of ideas. As the dialogues evolved, teachers provided direction for digressive discussions and regularly summarized the results. Although in some lessons only a small number of students participated in the discussion, teachers saw benefits for those who only listened:

I think a lot of students have never thought about it [reasons for different models of electrons], and some of them did not contribute much to the conversation either. But I had the feeling that no one thought it was nonsense to talk about it. Apparently, it's still interesting to listen to what others say. It is a way to construct your own understanding. That's what I like about such a conversation in a class. If you don't participate in the discussion because you're perhaps not that far yourself yet, you can still learn from others. (Hanna)

Concept questions were especially popular to address the role of models. For example, a question about the nature of electrons (see Fig. 1) was used by eight teachers to address the purpose of particle models in different situations. They collected students' answers using the online voting system (six teachers) or by raising hands (two teachers). Five teachers used concept questions to initiate small-group peer instruction, as intended in the instructional material; the others directly initiated a whole-class discussion. Reasons given for not implementing peer instruction were limited lesson time and the possibility to guide students' discussions.

I don't think that's a good idea[to have peer instruction]; a teacher is very much needed to remove misconceptions, to manage the discussions.[...] Maybe it will work eventually, but it is not efficient. (Ben)

The three teachers who addressed controversies in science in class used explanatory videos to introduce this topic: they appreciated this compact and informative type of presentation.

I actually knew very little about different interpretations. When I studied QP at university, we only did the math. So the videos are great, and those film-makers have more tools to visualize something than I have. (Hanna)

After the students had watched the short videos in class, the teachers engaged them in discussions about different interpretations, students' personal ideas, and the significance of controversies in science.

Liam and Ben, who taught parallel classes, experienced differences in the interest for certain topics between the two groups of students they taught and adapted their lessons accordingly. Ben described students' reactions on a short, animated video on quantum behavior:

The first group was very interested; they just thought: wow, something's happening here that I've never seen. They were motivated by the subject. But the other group 
thought: I don't understand what's happening. They weren't ready yet, I think, for the intellectual challenge.

We also observed teachers struggling to find the right way to teach NOS concepts. Karim, for example, was unhappy because his teaching goals did not seem to fit most of his students' expectations. He wanted to engage them in scientific conversations about QP interpretations, but he did not know how to achieve this goal:

I think for some students it's too hard, that the level of abstraction is actually too high. And for some students, it's too exhausting. [...] There are students with whom you can talk about this [QP interpretations] and who also see the added value. But for most of them, this year, it didn't work; there was no click. (Karim)

The provided short written task about the role of models was the least-used teaching strategy. Three teachers recognized the value of putting thoughts on paper and tried it in class, but only one teacher thought she was likely to use it again. The other teachers felt that organizing and discussing the writing was too time-consuming.

In summary, those teachers who addressed NOS aspects in their lessons regarded the following teaching or learning activities (supported by the instructional material) as useful: introducing the NOS-related topic through narrative or explanation, explanatory videos or concept questions, and further elaboration of the topic through discussion in small groups (peer instruction) or together with the whole class (dialogic discourse).

\section{Teachers' goals in QP lessons related to NOS aspects}

For the conceptual understanding of QP, most teachers regarded it "inevitable" that they would devote lesson time to NOS topics such as the role of models (in the context of wave-particle duality) and believed that NOS aspects could also serve other teaching goals (see Table IV). In the following, we compile the goals teachers mentioned for each NOS aspect.

Role of models.-Most teachers (8 out of 10) felt that it is crucial for students' understanding of QP concepts to actively discuss the role of scientific models.

For me, the biggest benefit is that it [the discussion on the nature of electrons] revealed that we use models which co-exist, and that you can explain different things with them, but that they are all useful scientific models. .... The students realized that it's a model you work with. That's new to most of them. Usually, they think: what you learn is how it is. (Liam)

Even in an 'intellectually less engaged' class, it was possible to stimulate students' thinking and argumentation.
There was a real discussion about that you can use one model for one situation and the other for another. [...] It was about the double-slit experiment. The question was: how do you know whether it is a wave or a particle. [...] If you manage to make them look at their own arguments, then you will get a fruitful discussion. (Karim)

Tentativeness of scientific knowledge.-This was considered useful by five teachers for achieving the goals to make students think, evoke their interest, or purely to explicitly address tentativeness as an important feature of scientific knowledge. Teachers found that tentativeness was easier to address in QP than in most other parts of the curriculum.

Sometimes you feel like it [science] is finished, and then all of a sudden, you discover a new world behind it and that it's still happening. Students can see this in quantum physics. For other subjects, you don't talk about it that much because it's mostly classical physics. (Nina)

A student said: "People in a hundred years' time may find our advanced models stupid and simple." It's nice when they realize this; it's very valuable. (Liam)

Controversies in science.-Five teachers believed that a discussion of controversies surrounding QP interpretations was a good way to evoke the curiosity and interest of "a certain kind" of students. While some students could enthusiastically philosophize about possible multiple universes, other students disengaged and preferred to be told what to learn. Only one teacher thought that it was essential for all students to address controversies as an inherent characteristic of science in the making:

In $Q P$, you must talk about different interpretations because otherwise, you don't give an honest picture of where we are right now. (Tim)

Human endeavor.-According to three teachers in our study, historical contexts and comprehensible human stories in QP are most suitable for evoking curiosity and interest. Several teachers mentioned that the physics textbook they used did not provide a link between the explanations of isolated QP concepts. Therefore, they assumed that understanding the development of theories and models as a human endeavor would help students to make sense of new content and connect it to prior knowledge.

It sticks better, I think. [...] historical facts about how they thought or who discovered what give students a framework in which they can place their knowledge. (Daan)

I think it might be even more important [than learning content knowledge] for them, for the future. This feeling: Science is a fascinating process for curious people [...]. 
That it's sometimes nice when reality turns out to be different from what you thought, and perhaps only then, they start to find it really interesting. (Ans)

\section{Limits of science}

Two teachers saw an opportunity to address the fact that science cannot answer all questions. They wanted to provoke students' astonishment and stimulate their thinking by stating that there is no answer to the question of what an electron really is.

In the past, I got the question: "What am I supposed to do with this? It is just old stuff." Well, now they see that we still can't explain everything. Students find this more exciting. (Tim)

To summarize, teachers' most important reason to address NOS aspects was to enhance students' understanding of QP concepts. The fragmented presentation of QP in physics textbooks was seen as problematic, and consequently, teachers felt that a more coherent narrative of scientists' struggles and wonder during the development of quantum theory is desirable. Teachers thought that this would not only arouse students' curiosity but also help them to relate QP to previously learned concepts and models. All participants mentioned additional educational goals, such as increasing students' self-efficacy and preparing students for the final exam, but teachers did not link these goals to addressed NOS aspects.

\section{DISCUSSION}

A large number of studies in science education have found that NOS is rarely addressed in secondary physics lessons because teachers are not familiar with NOS teaching $[40,72]$, find it irrelevant for students' physics learning [39], find it too difficult to teach [73] or consider it not possible because of time restrictions and preparation for national exams [72]. In our research, in contrast, most teachers indeed chose to address NOS aspects-especially the role of models-in their QP lessons even though they had no specific NOS training and NOS is not mandatory in the curriculum, and even though the lessons took place a few months before the national final exam. This remarkable result requires an analysis of teachers' reasons for addressing NOS aspects in their lessons. But first, we will reflect on possible limitations to the significance of our research.

The literature regularly reports that when interviewed, teachers over-estimate their in-class instructional practices [74,75]. In order to counteract this phenomenon, we observed several lessons to triangulate the interview results. These triangulations revealed no differences between actual and reported classroom activities. Moreover, the participants received the innovative QP learning materials without being specifically alerted to the embedded NOS aspects. Consequently, they had no reason to exaggerate their use of NOS. This is evident in the openness of the interviews. A telling example of this openness is the teacher who made no secret of not using a single NOS-related teaching activity. This attitude of the participants, together with the triangulation of the data, ensures the validity of our findings.

Nevertheless, there are two reasons why our results may not be representative of all physics teachers. First, all participants studied physics and graduated from teacher training programs in Dutch universities. Their master's degree in physics certifies broad academic subject knowledge. For countries where nonspecialists teach physics at the upper secondary level, the situation is likely to be different. Second, we recruited our volunteers at conferences on physics education. Therefore, we have a selfselected sample of teachers: As conference participants, their interest in new ideas for physics lessons is likely to be above average. Additionally, they volunteered because they were dissatisfied, at least to some extent, with the way QP is covered in textbooks. On the other hand, this self-selection is unrelated to the extent to which teachers practice NOS instruction in general. The participating physics teachers were not familiar with the term NOS; it is not a common topic in Dutch teacher training or physics degree programs. Accordingly, we have no reason to believe that our participants had much experience with NOS teaching.

The finding that teachers found it worthwhile to address-at least some-NOS aspects in their QP lessons suggests that our ecological instructional material meets Doyle and Ponder's requirements of practicability; it provides concrete and directly usable classroom activities and is adaptable to teachers' instructional preferences and specific classroom settings. In the introduction, we argued that teachers address NOS aspects in physics lessons only when they consider it practical [63] and helpful in achieving their teaching goals [64]. Therefore, we shall interpret the fact from this perspective.

We also explained in I.B.2 that teachers would develop their QP PCK with respect to Magnusson's first PCK subcategory, knowledge and beliefs about the goals and purposes of subject teaching [60]. Thus, if teachers consider NOS as a learning goal in itself, they will strive to infuse their QP teaching with NOS aspects. Indeed, research shows that teachers who want to integrate NOS into regular teaching often solely lack appropriate contexts and/or strategies [76]; our teaching materials provide both. The answer to our second research question (on teachers' goals) sheds light on whether the teachers in our study used QP primarily as a means to teach NOS or whether they used NOS aspects to achieve their goals in QP.

We identified five main goals that teachers have when addressing specific aspects of NOS in QP: (i) enhancement of conceptual understanding, (ii) stimulation of thinking or argumentation, (iii) arousal of curiosity and interest, (iv) connection to prior knowledge and contexts, and $(\mathrm{v})$ indication of how science works. Only the latter is 
primarily a NOS-related teaching goal, and only three teachers mentioned it in the interviews. This seemingly low NOS awareness might appear disappointing at first sight. However, it shows that teachers who are under pressure to prepare students for the final exam and working in a regular school system in which NOS is not examined have other priorities.

However, the encouraging finding of our study is that teachers discussed NOS aspects in class, not to pursue NOS as a goal in itself, but as a means of achieving other goals. This phenomenon is not mentioned in the literature on the teaching of other physics topics. As well as for students [52], it is likely that for teachers, the NOS-related topics are evident here because QP still contains many elements of science in the making. Issues such as the difficulty of finding a suitable model (for wave-particle duality) and the existence of controversies between scientists (on interpretations) do not appear in other topics in the physics curriculum. Teachers were certainly encouraged by the teaching materials to address NOS aspects in QP. Still, it is striking that many teachers in our study addressed NOS aspects that are not part of the final examination. Therefore, we believe the reason for the teachers' use of NOS in our study is likely to be due to their intentions to teach conceptual QP in a good way.

In addition to our findings on teachers' goals in QP lessons, the analysis of the teachers' preferred instructional strategies also provides important insights for NOS implementation in regular physics lessons. We found that dialogic discourse was the most commonly used activity (by 8 out of 10 teachers) to address various NOS aspects in QP lessons. This classroom activity allowed teachers to engage students while moderating the discussion. Interestingly, in a recent review McComas, Clough, and Nour [77] found that the most effective NOS instructions are "teacher practices that encourage students to be mentally engaged and think about NOS and that assist students to come to more accurate conclusions" (p. 70 emphasis in the original). While our study does not focus on the effect of instruction on students' NOS views, it is encouraging to notice that most of the participants chose a potentially effective NOS teaching strategy. In general, participants in our study were experienced teachers with a well-developed repertoire of topic-specific instructional strategies (part of PCK). These skills enabled them to use strategies like whole-class discussions or peer instruction, even for new, more challenging topics, such as philosophical discussions regarding QP interpretations.

The most popular practical tools for initiating dialogic discussions were the concept questions. The voting system prompted all students to think and decide on an answer. The engagement effect of concept questions (or clicker questions) is well-known in physics education research [69]. However, in contrast to traditional clicker questions, several NOS-related concept questions had no defined correct answer (see Fig. 1) but were intended to prompt discussion. Although previous research found that such uncertainty in QP classes can be unfamiliar and unsatisfactory for students [57], many teachers in our study managed to encourage students to participate in the discussions. From the literature, it is known that for experienced teachers, NOS implementation and the use of thought-provoking questions for discussions go hand in hand [78]. Again, the combination of teachers' general PCK (judging which concept questions are appropriate for discussion and skills to lead a group discussion) and the provided resources are likely to be responsible for this outcome.

Other frequently used instructional strategies for NOS aspects (used by 6 out of 10 teachers) were narratives and explanations. Teachers' preferences for these traditional strategies concur with research on classroom practice in upper secondary school physics [79]. Narratives and explanations give learners guidance and context, especially for new and counterintuitive concepts such as those in QP. In fact, narratives based on the history of science combined with classroom conversations are reported as powerful NOS teaching strategies [80,81]. Explanatory videos were an easy-to-use alternative. Teachers who considered introducing controversies about QP interpretations, but did not feel competent to explain them, appreciated the videos. This supports Kulgemeyer [82], who states that explanatory videos have potential learning advantages for students and teachers. Teachers can learn from experts how to introduce complex concepts.

We would also like to discuss two outcomes that might be considered as partial failures of our approach. First, only three teachers discussed controversies surrounding interpretations with the whole class, even though this is arguably essential for conceptual QP. This is similar to what Dunlop and Veneu [39] found: teachers regarded discussing controversies in science as suitable for "brighter" students only. Additionally, some teachers in our study mentioned that they felt uncomfortable because they knew little about different QP interpretations. Explanatory videos are a relatively successful way to support insecure teachers who want to address this challenging topic. Moreover, if we acknowledge the professionality of experienced teachers, it is reasonable that they can judge if a certain group of students is ready for philosophical discussions or not. This, indeed, indicates that an ecological intervention is beneficial. Second, one teacher, Milan, who holds a Ph.D. in quantum physics, did not address any NOS aspect in his lessons. He thought that the only acceptable context for QP was mathematical formalism. This pragmatic attitude is shared by many theoretical physicists but arguably not helpful to introduce students to QP for the first time [18]. This again is a consequence of our ecological approach; if a teacher is convinced that the offered instructional materials do not serve any purpose, they will not use them. To get them to implement some NOS aspects in their lessons, it would take more than just offering new 
instructional materials; the teacher would have to change their beliefs as well. We tend to accept that teachers are different and that it is not possible for everyone to teach in the desired way.

\section{CONCLUSIONS AND IMPLICATIONS}

We have argued that conceptual QP and NOS instruction can mutually support each other but that this approach is rarely implemented for various reasons. Our results show that experienced teachers-if provided with practical instructional material-find addressing specific NOS aspects beneficial for QP lessons.

\section{A. Concept questions for discussing the role of models in QP}

Our participants saw understanding the role of scientific models as critical for learning conceptual QP. To visualize quantum entities such as electrons or photons, they are sometimes modeled as classical particles and in other situations as waves. If students do not actively discuss the use and the function of models in QP, they are likely to be prone to various misunderstandings $[31,83]$. The teachers in our study found concept questions that challenged students' ideas about models particularly purposeful and practical to address this topic. To facilitate activating teaching strategies such as peer instruction or whole-class discussions, more concept questions on this topic would be helpful.

\section{B. NOS as connection between QP concepts and $Q P$ as context for NOS}

NOS aspects such as tentativeness, controversies, and science as a human endeavor had important roles in many of our participants' lessons: they served as contexts to introduce new QP concepts to students. Teachers who did not feel competent storytellers or those who lacked knowledge about these NOS aspects of QP felt supported by short videos that covered these aspects. In line with research on the connection between teachers' NOS implementation and their pedagogies and beliefs about science education [53,84], teachers in our study used dialogic practices which stimulate students' reasoning to achieve goals concerning students' intellectual and emotional engagement. Many of our teachers reported that these goals are beneficial for QP learning, and they found that addressing NOS aspects of QP is necessary for students' understanding. Hence, NOS aspects could serve as a coherent framework for all QP concepts at secondary school level, and at the same time, be an ideal example of contextualized NOS instruction. QP might therefore deserve a prominent position in physics curricula.

\section{Implications for supportive teaching materials}

Educational research is often criticized for having little effect on instructional practice [85]. Westbroek, Janssen, and Doyle [64] argue that educational reforms might be more successful (i.e., would be integrated into real classrooms) if the designers of the reform would focus on the goals of teachers. At the same time, they show that these core goals are situation and teacher specific. A one-size-fits-all pedagogy of educational reform will, therefore, never be successful. Our research shows that experienced teachers addressed NOS in different ways and to varying degrees, depending on their personal preferences and the perceived needs of their students. We believe that it is crucial to trust and acknowledge teachers' professionality. With this premise, our study shows that buffet-style materials in an ecological intervention can produce clear results because hard-to-change conditions such as curricula, lesson plans, access to digital devices, student populations, and the available teachers can be taken as they are.

We can conclude that any support for teaching conceptual QP - and probably other topics-should be practical, flexible, and adaptable to allow teachers to use it in different situations. In our view, teaching materials should, therefore, ideally serve as a database that supports various possible pedagogies from which experienced teachers can spontaneously create personalized lessons. We see particular potential for a collection of concept questions designed to spark discussions on NOS issues. Further research could show how best to develop and deliver buffet-style teaching materials and support teachers in working with them to prevent one-size-fits-all pedagogies.

\section{Implications for further research on teacher views}

There is considerable interest in students' difficulties in learning QP, and an increasing number of teaching approaches for secondary schools have been suggested and tested. However, little research has been performed on teachers' beliefs and practices, and the studies that do exist relate only to particular teaching situations [86-88]. As teachers are the most important facilitators of learning, their perspective is crucial. Therefore, we suggest more studies on teachers' goals and needs for conceptual QP in different educational systems.

\section{ACKNOWLEDGMENTS}

We would like to thank all physics teachers who let us visit their lessons and shared their thoughts with us in interviews and emails. The research for this article is supported by DUDOC ( $\mathrm{PhD}$ grant for teaching- and teacher-related studies), funded by the Dutch Ministry of Education, Culture, and Science (OCW). 
[1] H. K. E. Stadermann, E. van den Berg, and M. J. Goedhart, Analysis of secondary school quantum physics curricula of 15 different countries: Different perspectives on a challenging topic, Phys. Rev. Phys. Educ. Res. 15, 010130 (2019).

[2] G. Kalkanis, P. Hadzidaki, and D. Stavrou, An instructional model for a radical conceptual change towards quantum mechanics concepts, Sci. Educ. 87, 257 (2003).

[3] R. Müller and H. Wiesner, Teaching quantum mechanics on an introductory level, Am. J. Phys. 70, 200 (2002).

[4] R. V. Olsen, Introducing quantum mechanics in the upper secondary school: A study in Norway, Int. J. Sci. Educ. 24, 565 (2002).

[5] G. Pospiech, Philosophy and quantum mechanics in science teaching, Sci. Educ. (Dordr.) 12, 559 (2003).

[6] R. A. Muller, Physics and Technology for Future Presidents: An Introduction to the Essential Physics Every World Leader Needs to Know (Princeton University Press, Princeton, NJ, 2010).

[7] P. Bitzenbauer and J. Meyn, A new teaching concept on quantum physics in secondary schools, Phys. Educ. 55, 055031 (2020).

[8] A. J. Woitzik, Quanteninformationsverarbeitung in der gymnasialen Oberstufe, arXiv:2011.01029.

[9] M. Malgieri and P. Onorato, Educational reconstructions of quantum physics using the sum over paths approach with energy dependent propagators, J. Phys. Conf. Ser. 1929, 012047 (2021).

[10] C. Foti, D. Anttila, S. Maniscalco, and M. L. Chiofalo, Quantum physics literacy aimed at K12 and the general public, Universe 7, 86 (2021).

[11] C. Hughes, J. Isaacson, A. Perry, R. Sun, and J. Turner, Teaching quantum computing to high school students, arXiv:2004.07206.

[12] S. Satanassi, P. Fantini, R. Spada, and O. Levrini, Quantum computing for high school: an approach to interdisciplinary in STEM for teaching, J. Phys. Conf. Ser. 1929, 012053 (2021).

[13] M. Michelini and A. Stefanel, A path to build basic Quantum Mechanics ideas in the context of light polarization and learning outcomes of secondary students, J. Phys. Conf. Ser. 1929, 012052 (2021).

[14] R. Müller and O. Mishina, Milq-Quantum Physics in Secondary School (Springer International Publishing, Cham, 2021), p. 33, https://doi.org/10.1007/978-3-03078720-2_3.

[15] A. Garritz, Teaching the philosophical interpretations of quantum mechanics and quantum chemistry through controversies, Sci. Educ. (Dordr.) 22, 1787 (2013).

[16] I. M. Greca and O. Freire, Meeting the Challenge: Quantum Physics in Introductory Physics Courses (Springer, Dordrecht, Netherlands, 2014), p. 183.

[17] E. K. Henriksen, C. Angell, A. I. Vistnes, and B. Bungum, What Is light? Students' reflections on the wave-particle duality of light and the nature of physics, Sci. Educ. (Dordr.) 27, 81 (2018).

[18] A. Johansson, S. Andersson, M. Salminen-Karlsson, and M. Elmgren, "Shut up and calculate": The available discursive positions in quantum physics courses, Cult. Stud. Sci. Educ. 13, 205 (2018).
[19] D. Kaiser, Turning physicists into quantum mechanics, Phys. World 20, 28 (2007).

[20] N. G. van Kampen, The scandal of quantum mechanics, Am. J. Phys. 76, 989 (2008).

[21] O. Freire, A story without an ending: The quantum physics controversy 1950-1970, Sci. Educ. (Dordr.) 12, 573 (2003).

[22] C. Baily and N. D. Finkelstein, Teaching and understanding of quantum interpretations in modern physics courses, Phys. Rev. ST Phys. Educ. Res. 6, 010101 (2010).

[23] P. G. Hewitt, Millikan Lecture 1982: The missing essential-a conceptual understanding of physics, Am. J. Phys. 51, 305 (1983).

[24] D. Sands, Concepts and conceptual understanding: What are we talking about?, New Dir. Teaching Physical Sci. 10, 7 (2014).

[25] D. Allchin, Teaching the Nature of Science: Perspectives \& Resources (Ships Education Press, Saint Paul, MN, 2013).

[26] N. G. Lederman, Nature of Science: Past, Present, and Future (Lawrence Erlbaum Associates, Mahwah, NJ, 2007), Vol. 2, p. 831.

[27] D. Romero-Maltrana and S. Duarte, A new way to explore the nature of science: Meta-categories rather than lists, Res. Sci. Educ. (2020), https://doi.org/10.1007/s11165020-09940-y.

[28] R. L. Bell, Teaching the Nature of Science: Three Critical Questions (National Geographic School Publishing, Carmel, CA, 2009), Vol. 22, p. 1.

[29] G. Mesci and R. S. Schwartz, Changing preservice science teachers' views of nature of science: Why some conceptions may be more easily altered than others, Res. Sci. Educ. 47, 329 (2017).

[30] S. Gogolin and D. Krüger, Students' understanding of the nature and purpose of models, J. Res. Sci. Teach. 55, 1313 (2018).

[31] K. Krijtenburg-Lewerissa, H. J. Pol, A. Brinkman, and W. R. van Joolingen, Insights into teaching quantum mechanics in secondary and lower undergraduate education, Phys. Rev. Phys. Educ. Res. 13, 010109 (2017).

[32] O. Levrini and P. Fantini, Encountering productive forms of complexity in learning modern physics, Sci. Educ. (Dordr.) 22, 1895 (2013).

[33] E. Y. Weissman, A. Merzel, N. Katz, and I. Galili, Teaching quantum physics as a structured physics theory in high school, J. Phys. Conf. Ser. 1929, 012051 (2021).

[34] Z. Merali, Quantum physics: What is really real?, Nature (London) 521, 278 (2015).

[35] F. Abd-El-Khalick, Developing deeper understandings of nature of science: The impact of a philosophy of science course on preservice science teachers' views and instructional planning, Int. J. Sci. Educ. 27, 15 (2005).

[36] D. Gil and J. Solbes, The introduction of modern physics: overcoming a deformed vision of science, Int. J. Sci. Educ. 15, 255 (1993).

[37] B. Bungum, M. V. Bøe, and E. K. Henriksen, Quantum talk: How small-group discussions may enhance students' understanding in quantum physics, Sci. Educ. 102, 856 (2018).

[38] M. Niaz and M. A. Rodríguez, Improving learning by discussing controversies in 20th century physics, Phys. Educ. 37, 59 (2002). 
[39] L. Dunlop and F. Veneu, Controversies in science, Sci. Educ. (Dordr.) 28, 689 (2019).

[40] I. Galili and A. Hazan, Experts' views on using history and philosophy of science in the practice of physics instruction, Sci. Educ. (Dordr.) 10, 345 (2001).

[41] M. Leone, History of physics as a tool to detect the conceptual difficulties experienced by students: The case of simple electric circuits in primary education, Sci. Educ. (Dordr.) 23, 923 (2014).

[42] M. P. Clough, History and nature of science in science education (Sense Publishers, Rotterdam, Netherlands, 2017), Vol. 31, p. 39.

[43] C. Baily, N. D. Finkelstein, C. Singh, M. Sabella, and S. Rebello, Interpretation in quantum physics as hidden curriculum, AIP Conf. Proc. 1289, 69 (2010).

[44] A. K. Mohan, Philosophical standpoints of textbooks in quantum mechanics, Sci. Educ. (Dordr.) 29, 549 (2020).

[45] E. Etkina, A. Warren, and M. Gentile, The role of models in physics instruction, Phys. Teach. 44, 34 (2006).

[46] G. Ireson, The quantum understanding of pre-university physics students, Phys. Educ. 35, 15 (2000).

[47] M. S. Ubben and S. Heusler, Gestalt and functionality as independent dimensions of mental models in science, Res. Sci. Educ. (2019), https://doi.org/10.1007/s11165019-09892-y.

[48] J. Wiener, Science teachers' conceptions of atomic models, Eur. J. Sci. Math. Ed. 1, 67 (2020).

[49] A. R. Irwin, Historical case studies: Teaching the nature of science in context, Sci. Educ. 84, 5 (2000).

[50] N. Nouri and W. F. McComas, History of science (HOS) as a vehicle to communicate aspects of nature of science (NOS): Multiple cases of HOS instructors' perspectives regarding NOS, Res. Sci. Educ. (2019), https://doi.org/ 10.1007/s11165-019-09879-9.

[51] R. Khishfe, Explicit nature of science and argumentation instruction in the context of socioscientific issues: An effect on student learning and transfer, Int. J. Sci. Educ. 36, 974 (2014).

[52] H. K. E. Stadermann and M. J. Goedhart, Secondary school students' views of nature of science in quantum physics, Int. J. Sci. Educ. 42, 997 (2020).

[53] H. Bartholomew, J. Osborne, and M. Ratcliffe, Teaching students ideas-about-science: Five dimensions of effective practice, Sci. Educ. 88, 655 (2004).

[54] O. Kahana and T. Tal, Understanding of high-achieving science students on the nature of science, Int. J. STEM Educ. 1, 1 (2014).

[55] F. Abd-El-Khalick, J. Y. Myers, R. Summers, J. Brunner, N. Waight, N. Wahbeh, A. A. Zeineddin, and J. Belarmino, A longitudinal analysis of the extent and manner of representations of nature of science in U.S. high school biology and physics textbooks, J. Res. Sci. Teach. 54, 82 (2017).

[56] E. K. Henriksen, B. Bungum, C. Angell, C. W. Tellefsen, T. Frågåt, and M. V. Bøe, Relativity, quantum physics and philosophy in the upper secondary curriculum: Challenges, opportunities and proposed approaches, Phys. Educ. 49, 678 (2014).

[57] M. V. Bøe, E. K. Henriksen, and C. Angell, Actual versus implied physics students: How students from traditional physics classrooms related to an innovative approach to quantum physics, Sci. Educ. 102, 649 (2018).

[58] L. S. Shulman, Knowledge and teaching: Foundations of the new reform, Harv. Educ. Rev. 57, 1 (1987).

[59] L. S. Shulman, Those who understand: Knowledge growth in teaching, Educ. Res. 15, 4 (1986).

[60] S. Magnusson, J. Krajcik, and H. Borko, Nature, Sources, Development of Pedagogical Content Knowledge for Science Teaching (Springer, Dordrecht, 1999), p. 95.

[61] C. Faikhamta, The development of in-service science teachers' understandings of and orientations to teaching the nature of science within a PCK-based NOS course, Res. Sci. Educ. 43, 847 (2013).

[62] E. M. van Dijk, Understanding the heterogeneous nature of science: A comprehensive notion of PCK for scientific literacy, Sci. Educ. 98, 397 (2014).

[63] W. Doyle and G. A. Ponder, The practicality ethic in teacher decision-making, Interchange 8, 1 (1977).

[64] H. Westbroek, F. Janssen, and W. Doyle, Perfectly reasonable in a practical world: Understanding chemistry teacher responses to a change proposal, Res. Sci. Educ. 47, 1403 (2017).

[65] F. Janssen, H. Westbroek, and W. Doyle, The practical turn in teacher education: Designing a preparation sequence for core practice frames, J. Teach. Educ. 65, 195 (2014).

[66] F. Janssen, H. Westbroek, J. van Driel, and W. Doyle, How to make innovations practical, Teachers College record 115, 1 (2013), https://www.tcrecord.org/books/exec.asp? ContentID=17052.

[67] H. K. E. Stadermann and M. J. Goedhart, "Why don't you just tell us what light really is?" Easy-to-implement, adaptable instructional materials that link quantum physics to aspects of Nature of Science [Phys. Educ. (to be published)].

[68] W. Doyle, The uses of nonverbal behaviors: Toward an ecological model of classrooms, Merrill Palmer Q. 23, 179 (1977), https://www.jstor.org/stable/23084550.

[69] E. Mazur, Peer instruction: Getting students to think in class, AIP Conf. Proc. 399, 981 (1997).

[70] See Supplemental Material at http://link.aps.org/ supplemental/10.1103/PhysRevPhysEducRes.17.020132 for interview plan for teacher interviews.

[71] G. Guest, K. M. MacQueen, and E. E. Namey, Introduction to Applied Thematic Analysis (Sage Publications, Thousand Oaks, CA, 2012), p. 3.

[72] F. Abd-El-Khalick, R. L. Bell, and N. G. Lederman, The nature of science and instructional practice: Making the unnatural natural, Sci. Educ. 82, 417 (1998).

[73] A. Henke and D. Höttecke, Physics teachers' challenges in using history and philosophy of science in teaching, Sci. Educ. (Dordr.) 24, 349 (2015).

[74] M. T. Fitzgerald, L. Danaia, D. H. McKinnon, and S. Bartlett, Differences in perception between students and teachers of high school science: Implications for evaluations of teaching and classroom evaluation, Aust. J. Teach. Educ. 45, 73 (2020).

[75] T. Wubbels, M. Brekelmans, and H. P. Hooymayers, Do teacher ideals distort the self-reports of their interpersonal behavior?, Teach. Teach. Educ. 8, 47 (1992). 
[76] L. Leden and L. Hansson, Nature of science progression in school year 1-9: A case study of teachers' suggestions and rationales, Res. Sci. Educ. 49, 591 (2019).

[77] W. F. McComas, M. P. Clough, and N. Nouri, Nature of Science and Classroom Practice: A Review of the Literature with Implications for Effective NOS Instruction (Springer, New York, 2020), p. 67.

[78] B. C. Herman, M. P. Clough, and J. K. Olson, Association between experienced teachers' NOS implementation and reform-based practices, J. Sci. Teach. Educ. 24, 1077 (2013).

[79] D. Geelan, Teacher explanation of physics concepts: A video study, Res. Sci. Educ. 43, 1751 (2013).

[80] N. Kapsala and E. Mavrikaki, Storytelling as a Pedagogical Tool in Nature of Science Instruction (Springer, Cham, 2020), p. 485.

[81] C. T. Williams and D. W. Rudge, Effects of historical story telling on student understanding of nature of science, Sci. Educ. (Dordr.) 28, 1105 (2019).

[82] C. Kulgemeyer, A framework of effective science explanation videos informed by criteria for instructional explanations, Res. Sci. Educ. 50, 2441 (2018).
[83] K. Krijtenburg-Lewerissa, H. Pol, A.Brinkman, and W. van Joolingen, Secondary school students' misunderstandings of potential wells and tunneling, Phys. Rev. Phys. Educ. Res. 16, 010132 (2020).

[84] B. C. Herman, M. P. Clough, and J. K. Olson, Pedagogical reflections by secondary science teachers at different NOS implementation levels, Res. Sci. Educ. 47, 161 (2017).

[85] J. Schneider, From the Ivory Tower to the Schoolhouse: How Scholarship Becomes Common Knowledge in Education (Harvard Educational Publishing, Cambridge, MA, 2014).

[86] T. Bouchée, M. Thurlings, L. de Putter-Smits, and B. Pepin, Investigating teachers' and students' experiences of quantum physics lessons: opportunities and challenges, Res. Sci. Technol. Educ. 1 (2021).

[87] P. Bitzenbauer, Practitioners' views on new teaching material for introducing quantum optics in secondary schools, Phys. Educ. 56, 055008 (2021).

[88] M. V. Bøe, C. Angell, B. Bungum, and E. K. Henriksen, Quantum physics, history, philosophy and NoS in traditional physics classrooms, in Proceedings of the NARST Conference (2016), https://api.semanticscholar.org/ CorpusID: 171087145. 